\title{
Spatial co-localization of extreme weather events: a clear and
}

\section{present danger}

Rosalind Dodd ${ }^{1}$, David Chadwick ${ }^{2}$, Ian Harris ${ }^{2}$, Adrian Hines ${ }^{3}$, Dan Hollis ${ }^{3}$, Theo Economou $^{4,5}$, Dylan Gwynn-Jones ${ }^{6}$, John Scullion ${ }^{6}$, David Robinson ${ }^{7}$, and D.L. Jones ${ }^{2}$

${ }^{1}$ Lincoln University

${ }^{2}$ Bangor University

${ }^{3}$ Met Office

${ }^{4}$ Met Office Hadley Centre

${ }^{5}$ University of Exeter

${ }^{6}$ Aberystwyth University

${ }^{7}$ Centre for Ecology and Hydrology

May 29, 2020

\begin{abstract}
Extreme weather events have become a dominant feature of the narrative surrounding changes in global climate. with large impacts on ecosystem stability, functioning and resilience, however, understanding of their risk of co-occurrence at the regional scale is lacking. Based on the UK Met Office's long-term temperature and rainfall records, we present the first evidence demonstrating significant increases in the magnitude, direction of change and spatial co-localization of extreme weather events since 1961. Combining this new understanding with land use datasets allowed us to assess the likely consequences on future agricultural production and conservation priority areas. All land uses are impacted by the increasing risk of at least one extreme event and conservation areas were identified as hotspots of risk for the co-occurrence of multiple event types. Our findings provide a basis to regionally guide land use optimisation, land management practices and regulatory actions preserving ecosystem services against multiple climate threats.
\end{abstract}

\begin{abstract}
Extreme weather events have become a dominant feature of the narrative surrounding changes in global climate. with large impacts on ecosystem stability, functioning and resilience, however, understanding of their risk of co-occurrence at the regional scale is lacking. Based on the UK Met Office's long-term temperature and rainfall records, we present the first evidence demonstrating significant increases in the magnitude, direction of change and spatial co-localization of extreme weather events since 1961. Combining this new understanding with land use datasets allowed us to assess the likely consequences on future agricultural production and conservation priority areas. All land uses are impacted by the increasing risk of at least one extreme event and conservation areas were identified as hotspots of risk for the cooccurrence of multiple event types. Our findings provide a basis to regionally guide land use optimisation, land management practices and regulatory actions preserving ecosystem services against multiple climate threats.
\end{abstract}

Recent large flood and drought events have received global media attention. For example, unprecedented winter rainfall across the UK in 2013/14 resulted in extreme flooding and storm surges with large areas of agricultural land under water for more than 80 days (ADAS, 2014), while over $60 \%$ of the state of California's 
land area was under varying severity of drought from 2011 to 2017 (U.S. Government, 2018). Flooding and drought can have large economic impacts; the World Economic Forum has rated extreme weather events as the most significant risk facing humanity (World Economic Forum, 2018). Losses to the UK agricultural sector of $£ 180$ million were reported as a result of the 1995 drought and associated heatwave (Environment Agency, 2006), while the 2013/14 flood led to losses of over $£ 20$ million (ADAS, 2014). Similarly, the total economic impact of the European heatwave in 2013 was estimated at 11 billion Euros (Environment Agency, 2006), while extreme snow was estimated to cost the US economy up to $\$ 3$ billion in 2016 (Lee and Lee, 2019). Natural ecosystems are also vulnerable, for example, record heat and dry conditions in 2010/2011 led to a sudden collapse of large areas of Australian eucalypt forest previously considered to be resilient to drought (Matusick et al., 2013). Furthermore, the hot and dry conditions of 2018-19 in the UK resulted in unprecedented wildfires in the globally rare moorland habitat with 135 individual fires burning 29,334 ha of land (E.F.F.I.S., 2019). In 2019, hot and dry conditions in Australia resulted in the generation of mega-fires with unprecedented sizes and number of fires covering at least 3.8 million ha of temperate forest (Nolan et al. 2020)

While there is a wealth of evidence that temperatures are increasing, the pattern for rainfall is uncertain (IPCC, 2013) but predicted to become temporally uneven with the majority of annual precipitation totals occurring in a small number of intense events (Pendergrass and Knutti, 2018). For many regions of the UK, climate models and historical observations indicate that the frequency, intensity (Thompson et al. 2017; Kendon et al. 2014) and duration (Roudier et al. 2016) of winter rainfall has increased, along with the incidence and intensity of short burst summer downpours (ADAS, 2014) and the kinetic energy of autumn rainfall (Alfieri et al., 2015). Models also predict an increase in the frequency of short-term droughts of three to six months in duration (Burke et al. 2010). These all have implications for agriculture, conservation and human health.

To date, the majority of studies investigating the risk of extreme weather events have focused on the global or national scale, and often only on a single event type. There is greater uncertainty in changes at the regional scale where the immediate impacts will be felt (Marotzke et al. 2017). Spatial variation in weather patterns can be large and analysis at the national scale masks regional differences in the risk of occurrence and the expected event type (Zampieri et al., 2017). Furthermore, extreme events might not occur in isolation and there are an increasing number of examples of direct transitions from one extreme weather regime to another (e.g. flood to drought or vice versa ) (Mahony and Cannon, 2018; Swain et al. 2018; Loecke et al., 2017). In the UK, heavy spring rainfall in 2012 led to 78 days of flooding, while 98 days of official drought were declared the following summer which the media dubbed 'the wettest drought on record' (Channel 4 News, 2012). In 2019 there were 5,600 flood warnings across England while groundwater reserves were depleted in 25 areas (The Guardian, 2019)( Such events have highlighted the need for stakeholders, including farmers, water companies, forestry and environmental protection and conservation bodies to prepare for the possibility of both flooding and drought within the same year. So called 'compound events' have been identified by the World Climate Research Program as a research priority (Alexander et al. 2016) and are likely to have disproportionately severe impacts on ecosystems, potentially tipping ecosystem functions into new trajectories (Johnstone et al. 2016).

To safeguard vulnerable ecosystems and the services they provide, adaption in management may be required. However, the specific strategy employed will vary depending on the event type. For example, the re-introduction of grazing livestock to moorland could reduce fire risk during dry, hot summers but could also increase the risk of compaction during wet periods increasing subsequent flood risk. Similarly, planting trees to sequester carbon may increase fire risk under dry conditions leading to a potential reduction in air quality, water quality and human health if planted in the wrong place (Lui et al. 2017).

To advise stakeholders and guide policy we need to understand the regional risk posed by different (single and multiple) extreme events and identify where they might impact delivery of ecosystem services (e.g. food security, biodiversity, carbon storage) by different land use types. In this study, we utilised the historical UK weather record held by the UK Met Office National Climate Information Centre to examine, for the first time, 
the change in frequency and distribution of, and interaction between, indicators of four weather extremes; extreme heat, extreme cold, high rainfall and low rainfall, based on thresholds indicative of heatwaves, cold snaps, floods and droughts, between two time periods 1961-1988 and 1989-2016. We integrated the results from this analysis with national land cover data to identify extreme weather hotspots in relation to ecosystem type and their ability to deliver different ecosystem services.

These datasets were statistically interrogated to answer four key questions: (1) Has the frequency of extreme events in the UK increased between the two time periods? (2) Are there hotspots where the annual risk of occurrence for two or more event types has increased? (3) Are there areas of the UK where the probability of occurrence of two or more types of event within the same year has increased? and (4) Are some vulnerable ecosystems more exposed to changes in risk of increased numbers of events occurring than others?

Through this analysis, we provide evidence for the perceived increase in the frequency of extreme events across the UK. To date, most studies of this nature have focused on the incidence, or impact, at the national scale. Our results show strong regional variation in the direction and magnitude of change enabling the production of national risk maps which can be used by stakeholders to guide land management and policy that promotes adaptation to protect the delivery of ecosystem services from different land uses.

Our analysis shows that between the two 28-year periods of high resolution meteorological records there has been a notable change in the frequency of threshold exceedance across the UK with strong regional response patterns (Fig. 1). Temperature metrics showed the largest and most widespread response but the direction of change varied. For extreme heat events, there was a significant increase in the mean number of events during the last 28 years, with the south east of England experiencing the largest change, corresponding to on average 1.87 additional events each year. Significant increases $(0.68-1.36)$ in the mean number of extreme events also occurred across most of England, except the north west and across the east of Northern Ireland, and the far north of Scotland. Concurrently, the frequency of extreme cold events decreased across all regions except for much of Wales and small regions of south west England and northern Scotland. The magnitude of change was greater than that for heat extremes, ranging from 1-2.3 fewer events each year. Response patterns in rainfall extremes were weaker than for temperature; this is consistent with the large body of research showing mixed results for predicted changes in rainfall patterns across the globe (Alfieri et al. 2015). However, the results show a significant increase in wet extremes ranging from 1.0 - 1.6 additional events each year in western Scotland to 0.8 - 1.0 additional events in the Welsh border region, along parts of the south coast of England and East Anglia, and in western Northern Ireland. The change in extreme dry events was small with no significant increase overall and a decrease of 0.9 events in the far north for Scotland. However, a strong spatial pattern in extreme dry events did emerge, reflecting the changes in heat events with an increase of up to 0.5 events in south east England.

These changes in threshold exceedances for temperature and rainfall provide statistical evidence underpinning the perceived increase in UK heatwaves, floods and droughts over the past decade and provide insight into which regions are most at risk. While the changes in temperature drivers relate directly to heat waves or cold snaps, the use of precipitation as a proxy for flood or drought events is less robust. However, an increase in extremely wet periods in Scotland, parts of southern England and Wales and Northern Ireland will heighten flood risk. Furthermore, runoff extremes have been shown to increase more quickly than precipitation extremes in a warming climate, and increases in rainfall are likely to underestimate the risk of flash flood events (Yin et al., 2018). These results corroborate the recent analysis of observed river discharge trends between 1960 and 2010 which found the largest increase in flood discharge in these areas (Yin et al., 2018). Similarly, drought risk is a function of both rainfall and temperature with prolonged high temperatures exacerbating soil dryness and providing feedback loops further reducing rainfall, increasing surface temperatures and promoting fire risk(Teuling, 2018). Seasonal analysis of changes in extreme dry events revealed that the greatest change occurs during spring (Fig. S1) when new season growth begins, and is a vital period for sufficient soil moisture supply for agricultural crops. Spring drought has been shown to be more detrimental to plant production compared to summer drought conditions across a range of ecosystems (Song et al., 2019). Increases in dry spring events may be exacerbated by a spatially coupled increase in the 
number of periods of suitable winter growing conditions utilising water reserves built up during preceding wetter seasons (Fig. 2). Whilst not statistically significant (at $p<0.05$ ), the indicative combination of i) increased dry events with ii) an increase in heat events, and iii) increased winter growing periods, points towards a heightened drought risk in the future, especially in the south east of England where these metrics showed the greatest increase. Furthermore, the probability that a heat event and a dry event will occur within the same year was high and ranged from 0.80 to 0.98 in this area (Fig. S2). Although the evidence for increased extreme dry events, from this analysis is weak, it corroborates recent modelling indicating high drought vulnerability in East of England based on reported historical agricultural impacts (Parsons et al., $2019)^{[30]}$

The environmental impact of this increased frequency in extreme events depends on the land use and the biodiversity and ecosystem services it is expected to deliver. The response may vary, in magnitude and direction, based on the type of ecosystem and the dominant services it provides (Table 1, Table S1). We grouped the UK land cover categories (Rowland et al. 2015) into four broad classes each providing specific ecosystem services and levels of biodiversity: (1) Agriculture, incorporating arable/horticultural and improved grasslands (provisioning), (2) Woodlands, incorporating broadleaf and coniferous woodlands (provisioning, regulating and biodiversity), (3) Conservation, incorporating National Parks and Sites of Special Scientific Interest (SSSIs) (supporting regulating and biodiversity), (4) Carbon stores, incorporating heathland, heath grasslands and bogs (regulating).

The reduction in frequency of cold events (i.e. less frosts and snow) shows an impact across all ecosystem types, ranging from $64 \%$ of all the land in SSSIs to $>80 \%$ of the total area under arable land use, respectively. Simplistically, it might be assumed that a reduction in winter cold events would be beneficial. However, many plants rely on low winter temperatures for vernalisation and warmer winters can cause increased pest and disease risk, loss of cold acclimation, asynchronicity of biological lifecycles and increased runoff (Table 1).

Agricultural systems and broadleaf forests represented the largest proportion of the total land area at increased risk of extreme heat events and the arable sector in particular appears to the most affected with $83 \%$ of the total area at risk (Fig. 3a). This reflects the large dominance of arable land use in the East of England. Furthermore, recent research suggests that heat extremes have a larger impact on grain yields than extremes in precipitation, highlighting the risk to arable systems (Vogel et al., 2019) and, hot dry spells can influence agricultural water use, especially under cropping. In the period between 2000 and 2017, the highest 2 years for abstraction for the purpose of spray irrigation correspond with the lowest 2 years of annual levels of rainfall (DEFRA, 2019a). Temperature extremes also dominated in improved grasslands, with $56 \%$ of the total area exposed to increase risk of extreme heat which directly impacts on livestock production. However, the proportion of grassland exposed to increases in extreme rainfall, and therefore flooding, was greater than in arable systems. Soil carbon (C) stores and coniferous forests appear to be most at risk of extreme rain and flooding, with increased frequency of events occurring across $35-55 \%$ of the total area. Forests are commonly proposed as mitigation strategies to reduce flood risk through interception of rainfall and increased soil infiltration (Stratford et al., 2017). However, extreme rainfall events often override this increased infiltration capacity and the potential to reduce the severity of major floods is limited. When flooding does occur, the impact can be severe in commercial forestry operations with largescale erosion and damage downstream from woody debris. For soil $\mathrm{C}$ stores, reduced extreme cold and extreme rainfall present the largest risk. This has large implications for the $\mathrm{C}$ cycle and is likely to increase the release of soil $\mathrm{C}$ and decrease sequestration through and increase in wet-drying cycles and microbial respiration and increased erosion losses (Petrakis et al., 2017; Reichstein et al., 2013; Kim et al., 2012; Schimel et al., 2007) (Table 1). Our analysis also indicates that large expanses of upland bog or lowland fen peat are located in regions experiencing higher temperatures, droughts and therefore potential fire risk. These events threaten to exacerbate greenhouse gas emissions and destabilization of terrestrial C stores.

Specific regions of the UK show a significant increase in frequency of more than one extreme event type (Fig. 4). Risk hotspots, with significant increased frequency of three threshold exceedances are identified in the south coast of England, areas in the Welsh borders and the north east of England, highlighting areas most 
at risk of unexpected ecosystem response and largescale impacts on function (Table 1). Land of high nature value appears to be at most risk of multiple extreme event types with all three stress indicators increasing in frequency in 24 and $21 \%$ of the total area covered by National Parks and SSSIs (Fig. 3b). Due to the importance of these sites as niche habitats for rare or endangered species this could have severe impacts on biodiversity and genetic resources. This was seen following the 1995 UK drought which led to a shift in butterfly communities from vulnerable specialised species to widespread generalist species (De Palma et al., 2017).

Exposure to an extreme event can make ecosystems more susceptible to a subsequent stress, magnifying impacts (Hohner et al., 2019; Ksudhal et al., 2018; Mazdiyasni and AghaKouchak, 2015; Zscheischler et al., 2014) with the potential to decrease the threshold by which climatic metrics, such as precipitation amount, generate an extreme event, such as flood or drought (DEFRA, 2019). Our results show that the overall UK mean increase in the probability of all four event types occurring with the same year low at 0.275 . However, the impact on ecosystem function would likely be extreme. The increase in frequency of extreme heat events was the dominant driver of the response pattern, with the highest probabilities in the south east of the UK and the lowest probabilities in Scotland, Wales, Northern Ireland and north-west England (Table S2; Fig. S2).

To illustrate the impact on agriculture, we have taken the UK arable sector as a case study since the combination of adverse weather conditions can magnify the impacts on agricultural production. In particular, the combination of extreme wet spells and extreme dry spells within the same year has been shown to be particularly detrimental for crops. In 2017, there was an $8.3 \%, 17 \%$ and $19 \%$ reduction in income in England from key three crops, wheat, sugar beet and potatoes respectively. This was attributed, in part, due to reduced yields caused by wet spring conditions, hot dry summer and heavy autumn rains during harvest ${ }^{[45]}$. Reductions in yields reduced the export value of wheat by $73 \%$ and 84\% in 2017 and 2018 respectively, and increased the import expenditure by $38 \%$ and $79 \%$ respectively (DEFRA, 2018). The majority of the UK's arable and horticultural land area is in the East of England, with $28 \%$ of total wheat production and $62 \%$ of sugar beet production located in the South East, and East Anglia accounting for one third of England's potato crop (DEFRA, 2018). The probability that extreme hot, dry and wet events will occur within the same year is highest for this region of the country and ranges from 0.69-0.99 (Fig. S2) highlighting the vulnerability of this sector to future climatic risk.

Globally, societies are facing unprecedented and complex threats to food and water security, infrastructure and well-being due to climate change. The increased frequency of multiple extreme events across different land uses identified by our analysis is likely to have detrimental impacts on the ecosystem service provision. While some benefits to service provision have been identified, these are likely to be out-weighed by the negative impacts (Table 1). In May 2019, the UK government declared a state of climate emergency that was swiftly followed by Ireland, France and Canada. Furthermore, large-scale land use change has been identified as a strategy for the UK to meet its emission reductions in the Paris Agreement (Committee on Climate Change, 2018), and its recent target of net zero emissions by 2050. The evidence herein provides vital information on the vulnerability of different areas and economic sectors to climate extremes and should be used by UK policy makers, farm advisers and environmental agencies to develop adaption strategies and land use change policy tailored to the specific extreme event threat, based on location and ecosystem type. This research highlights the importance of considering the change in exposure of land to (combinations of) extreme weather at the regional scale and adoption of a similar approach in other countries could inform the safeguarding of the vital ecosystem services on which society depends.

\section{Methods}

\section{Dataset used in this study}

We used the $5 \mathrm{~km}$ scale historical UK weather record held by the UK Met Office's National Climate Information Centre (Perry and Hollis, 2005). This gridded dataset covers the whole of the UK and includes daily maximum and minimum temperature and rainfall data from observation stations from 1960 to 2016. 
We developed indices relating to the risk of occurrence of four extreme weather events, namely (i) heat waves, (ii) cold snaps, (iii) extreme rainfall (flood), and (iv) low rainfall (drought). We employed a threshold approach and for each grid point extracted the frequency each year that the five day rolling mean temperature or rainfall exceeded this threshold for a set number of days. We split the resulting dataset into two 27 year time periods, 1961-1988 and 1989-2016, reflecting the Met Office's definition of long-term averages for weather data of 30 years (World Meteorological Organization, 2017), while keeping two discrete time periods of equal length.

\section{Setting extreme weather thresholds}

With the exception of the index relating to drought, thresholds were set based on deviation from the mean value of the whole dataset for each grid point. Maximum daily temperature or rainfall above the $95^{\text {th }}$ percentile and minimum daily temperatures below the $5^{\text {th }}$ percentile were considered extreme (World Meteorological Organization, $2017 \mathrm{a}^{[49]}$. Temperature and rainfall conditions are spatially variable across the UK and utilising percentiles as the threshold instead of a fixed value allows for regional variation in normal conditions. What is considered an extreme temperature or rainfall amount in one location may be relatively normal for another and it is likely that the largest impact on ecosystem function occurs when conditions are outside the norm rather than at a fixed value (Zhang et al., 2011).

Using this approach, the following thresholds were proposed as an event metric for extreme heat, cold and rainfall based on recommendations provided in the draft guidelines on the definition and monitoring of extreme weather and climate events produced by the World Meteorological Organization (WMO) (World Meteorological Organization, 2018a).

Heat: The number of times each year where the 5-day rolling mean of the maximum temperature exceeds the $95^{\text {th }}$ percentile of the whole dataset for 3 or more days.

Cold: The number of times each year where the 5-day rolling mean of the minimum temperature is below the $5^{\text {th }}$ percentile of the whole dataset for 3 or more days.

Extreme rainfall: The number of times each year where the 5-day rolling mean of the daily rainfall total is above the $95^{\text {th }}$ percentile for 3 or more days.

Low rainfall: The number of times each year where the 5-day rolling mean of total daily precipitation was below $1 \mathrm{~mm}$ for 14 days or more, based on a historical definition of agricultural drought used in Britain of rainfall below $1 \mathrm{~mm}$ for more than 15 days (Heim et al., 2002).

For this study, extreme rainfall was used as a proxy for flood risk. While it is recognised that flood generation encompasses many complex variables, including the hydrology and topography of the landscape, we focus on rainfall totals as an indicator of the change in risk potential. Daily rainfall totals in the preceding 0 to 3 days was shown to be the best predictor of river flood events across the Swiss Alps (Froidevaux et al., 2015). In the UK the total rainfall over 3 days was linked to 40 year maximum peak river discharge and recorded flood events in 3 out of 4 studied river catchments (Lavers et al., 2011). In China, persistent extreme precipitation events, considered to indicate high damage potential were defined as daily precipitation total above $50 \mathrm{~mm}$ for 3 or more days (Chen and Zhai, 2013). Similarly to the flood index, we used rainfall as a proxy indicator for drought risk. However, prolonged dry spells, rather than a deviation from the minimum rainfall long-term average are likely to be more significant in reducing soil moisture content and increasing risk of drought.

\section{Data analysis}

To investigate how the risk of each event type occurring within a year has changed between the two time periods, we plotted the change in the number of events between 1961-1988 and 1989-2016 on a gridded map of the UK, using output from the following model:

Single extreme weather event models: Generalized Additive Models or GAMs (Wood, 2017) were adopted as the modelling framework to characterise the trends in extreme event frequency. This well-established class of models allows for flexible characterisation of the spatio-temporal variability of a modelled environmental 
variable and has been used extensively to characterise natural hazards (Youndman and Economou, 2017) and in modelling environmental variables more generally (Wood, 2017). The data extracted relates to counts of events $y_{s, t}$ in grid cell $s$ and year $t$. To capture the variability of these counts in space and time, we assume a Poisson distribution with mean $\mu_{s, t}$ : the mean count in cell $s$ and year $t$. This mean is then characterised as a function of $s$ and $t$ in the following way:

$\log \left(\mu_{\mathrm{S}, \tau}\right)=\mu_{0}+f_{T}(t)+f_{S}(s)+f_{S, T}(s, t)$

The three unknown functions $f(\cdot)$ were all assumed smooth in the sense of capturing spatial and temporal variation that does not change too extremely in neighbouring locations or points in time. Much more extreme variation was captured by the random element of the model (i.e. the Poisson variability). The one dimensional function $f_{T}(t)$ of time (in years) was used to capture the overall temporal trend in the counts across space, whereas $f_{S}(s)$, a two-dimensional function of longitude and latitude was used to capture overall spatial variability (across time). Lastly, the three dimensional $f_{S, T}(s, t)$ captured spatio-temporal variability, in the sense of allowing for different spatial patterns for each time point (year). This captured inter-annual variability in the spatial patterns exhibited by $y_{s, t}$. Such models were estimated using the statistical language R (R Core Team, 2019) and the package mgcv (Wood et al., 2016).

The model was used to estimate event counts $y_{s, t}$ using the simulation from the predictive distribution $p$ $\left(y_{s, t}\right)$. This distribution captures both the Poisson variability in the counts as well as the uncertainty in estimating the three unknown functions. From this, we computed the distribution of the difference in mean counts between the two time periods, i.e. mean count in 1989-2016 less the mean count in 1961-1988. This difference was plotted as a Z score in figure 1 and figure 2 and figure S1. Probabilities where this difference is not zero at the $5 \%$ significance level are termed significant (analogous to a $\mathrm{p}$ value $<0.05$ ).

The impact of rainfall on soil moisture is controlled to some extent by seasonality of resource use. Additionally, the impact of soil moisture deficit on plant response is related to growth stage. Therefore, we also investigated the change in dry spells at the seasonal time scale. To do this, we split each year into four, three-month time periods; Spring (March, April, May), Summer (June, July, August), Autumn (September, October, November) and Winter (December, January, February), and carried out the above data analysis on the defined threshold for low rainfall in each season.

\section{Multiple event interactions}

To investigate how the potential for the interaction of different extreme events types has changed, we employed two methods to answer two slightly different questions.

Are there areas of the UK where the annual risk of occurrence at an individual grid point has increased between the two time periods (1961-1988 and 1989-2016) for two or more of the classes of extreme event?

To investigate this question we overlaid the grid points from the single event analysis to determine those points where there was a significant increase in two or more event metrics.

Are there areas of the UK where the risk of two or more different types of extreme event occurring at an individual grid point within a single year has increased between the two time periods?

To investigate this question we extended the methodology used for the single events to allow for dependence between them, and investigated how the probability of events of two or more types occurring within a single year has changed over the two time periods.

\section{Multiple extreme weather event models}

To quantify the correlation between the counts of the various stress events we used the single event models to detrend the data for each event metric and create a transformed data set which does not exhibit spatiotemporal variability. Using the transformed data, the dependency across the various event metrics was quantified using correlation. The single event Poisson models were used to transform the original data $y_{s, t}$ (for each stress) to the scale of a Gaussian random variable with mean zero and variance one. At that 
scale, all spatial and temporal variability has been factored out and the sample correlations between the transformed counts for each event are estimates of the dependency between each event.

A modified simulation technique was employed to sample from the predictive distribution of the counts for each event, allowing for the correlation between them. Firstly, we generated random samples of the data at the detrended scale, respecting the correlation between the event metrics at this scale. Then, we transformed these samples back to original scale of the data to obtain a set of simulated counts in each grid cell and year, thus maintaining both the spatio-temporal variability in each event but also the correlation between event metrics.

The thresholds were set as the sample mean of each event metric across all grid cells and years. The joint probability that the annual mean count of two or more event categories exceeds a particular threshold was then determined. Comparison of differences in these probabilities between 1961-1988 and 1989-2016 lie in the region between -1 and 1 , and conveys information about whether the risk of two or more stress events occurring within one year has increased. Significant changes are ones that are above 0.05 or below -0.05 .

\section{Spatial mapping of the extreme weather event datasets}

Data were exported from $\mathrm{R}$ as ascii text files with grid cell centroid locations provided as absolute integer coordinates in British National Grid projection to facilitate import into ArcGIS 10.5 for visualisation and further analyses. Null values (NA) representing offshore locations were recoded to (-9999), ensuring compliance with numeric format prior to import. The point locations were plotted and then spatially joined to a pre-calculated vector $5 \mathrm{~km}$ grid, whereupon joined null values and their corresponding grid squares were identified and removed. The resulting datasets were then used to create thematic maps.

Geoprocessing (clipping) was used to extract underlying published land cover data (Rowland et al, 2017). The resulting land cover data required planimetric areas to be re-calculated, and these were subsequently summarized by ecosystem type and aggregate area. The UK land cover categories (Rowland et al. 2017) were grouped into four broad classes each providing specific ecosystem services and levels of biodiversity: (1) Agriculture, incorporating arable/horticultural and improved grasslands (provisioning), (2) Woodlands, incorporating broadleaf and coniferous woodlands (provisioning, regulating, and biodiversity), (3) Conservation, incorporating National Parks and Sites of Special Scientific Interest (SSSIs) (supporting, regulating and biodiversity), (4) Carbon stores, incorporating heathland, heath grasslands and bogs (regulating).

Where the analyses had revealed significant change, a field attribute selection was used to identify the corresponding grid squares, extracted, and then exported as separate geospatial datasets. To facilitate further quantification of land cover types affected, the boundaries between resulting significant grid squares were dissolved, so that only the perimeters of aggregated squares remained. These two datasets were combined to produce a map for each of the four land cover categories overlain with areas of significant increase in frequency of each extreme event metric.

\section{References}

ADAS, (2014), The Economic Impact of 2014 Winter Floods on Agriculture in England. ADAS: Wolverhamption, UK. p. 46pp.

Alexander, L., X. Zhang, G. Hegerl, S. Senevirantne, A. Behrangi, E. Fischer, (2016), Implementation Plan for WCRP Grand Challenge on Understanding and Predicting Weather and Climate Extremes. The "Extremes Grand Challenge", W.C.R. Program, Editor. Geneva. pp. 33

Alfieri, L., P. Burek, L. Feyen, and G. Forzieri, (2015), Global warming increases the frequency of river floods in Europe. Hydrology and Earth System Sciences, 19: 2247-2260.

Burke, E.J., R.H. Perry, and S.J. Brown, (2010), An extreme value analysis of UK drought and projections of change in the future. Journal of Hydrology, 388: 131-143. 
Channel 4 News. (2012), The wettest drought on record . [cited 2018 14/05/18]; Available from: https://www.channel4.com/news/the-wettest-drought-on-record

Chen, Y. and P. Zhai, (2013), Persistent extreme precipitation events in China during 1951-2010. Climate Research, 57: 143-153.

Committee on Climate Change. (2018), Land use: Reducing emissions and preparing for climate change. 2018, Committe on Climate Change . pp 1 - 100.

DEFRA, (2019), Water Abstraction Statisitics: England 2000 - 2017. p. 4.

DEFRA, (2019), The Future of Farming and Environment Evidence Compendium. p. 122.

DEFRA, (2018) Agriculture in the U.K. 2018 . p. 119.

De Palma, A., R.L.H. Dennis, T. Brereton, S.R. Leather, and T.H. Oliver, (2017), Large reorganizations in butterfly communities during an extreme weather event. Ecography, 40: 577-5852

E.F.F.I.S. (2019); Available from: http://effis.jrc.ec.europa.eu/static/effis_stats/effis-estimates/GB, (acessed $12 / 07 / 19)$

Environment Agency, (2006), The impact of climate change on severe droughts. Major droughts in England and Wales from 1800 and evidence of impact. Bristol UK. p. 54pp.

Fowler, H.J. and C.G. Kilsby, (2003) A regional frequency analysis of United Kingdom extreme rainfall from 1961 to 2000. International Journal of Climatology , 23: 1313-1334.

Froidevaux, P., J. Schwanbeck, R.M. Weingartner, C. Chevalier, O. Martins, (2015) Flood triggering in Switzerland: The role of daily to monthly preceding precipitation. Hydrology and Earth System Sciences, 19: 3903-3924.

Heim, R.R., (2002), A Review of Twentieth-Century Drought Indices Used in the United States. Bulletin of the American Meteorological Society, 83:1149-1166.

Hohner, A.K., C.C. Rhoades, P. Wilkerson, F.L. Rosario-Ortiz, (2019), Wildfires Alter Forest Watersheds and Threaten Drinking Water Quality. Accounts of Chemical Research , 52: 1234-1244.

IPCC, (2013), Climate Change 2013: The Physical Science Basis. Contribution of Working Group I to the Fifth Assessment Report of the Intergovernmental Panel on Climate Change, T.F. Stocker, et al., Editors. Cambridge University Press, Cambridge, United Kingdom and New York, NY, USA. p. 1535pp.

Johnstone, J.F., C.D. Allen, J.F. Franklin, L.E. Frelich, B.J. Harvey, P.E. Higuera et al., (2016), Changing disturbance regimes, ecological memory, and forest resilience. Frontiers in Ecology and the Environment 14: 369-378.

Kaushal, S.S., A.J. Gold, S. Bernal, and J.L Tank, (2018), Diverse water quality responses to extreme climate events: an introduction.Biogeochemistry, 141: 273-279.

Kendon, E.J., N.M. Roberts, H.J. Fowler, M.J. Roberts, S.C. Chan, and C.A. Senior, (2014) Heavier summer downpours with climate change revealed by weather forecast resolution model. Nature Climate Change , 4: 570-576.

Kim, D.G., R. Vargas, B. Bond-Lamberty, and M.R. Turetsky, (2012), Effects of soil rewetting and thawing on soil gas fluxes: a review of current literature and suggestions for future research.Biogeosciences , 9: 2459-2483.

Lavers, D.A., R.P. Allan, E.F. Wood, G. Villarini, D.J. Brayshaw, A.J. Wade, (2011), Winter floods in Britain are connected to atmospheric rivers. Geophysical Research Letters , 38. L23803

Lee, M. and J. Lee, (2019), Trend and Return Level of Extreme Snow Events in New York City. The American Statistician. DOI: 10.1080/00031305.2019.1592780 
Liu, X., L.G. Huey, R.J Yokelson, V. Selimovic, I.J. Simpson, M. Müller, J.L. Jimenez, et al. , (2017), Airborne measurements of western U.S. wildfire emissions: Comparison with prescribed burning and air quality implications. Journal of Geophysical Research: Atmospheres , 122: 6108-6129.

Loecke, T.D., A.J. Burgin, D.A. Riveros-Iregui, A.S. Ward, S.A. Thomas, C.A. Davis, et al., (2017), Weather whiplash in agricultural regions drives deterioration of water quality. Biogeochemistry, 133: 7-15.

Mahony, C.R. and A.J. Cannon, (2018), Wetter summers can intensify departures from natural variability in a warming climate. Nature Communications , 9: 783.

Marotzke, J., C. Jakob, S. Bony, P.A. Dirmeyer, P.A. O'Gorman, E. Hawkins, et al., (2017), Climate research must sharpen its view. Nature Climate Change, 7: 89-91.

Matusick G., K.X. Ruthrof, C.N. Brouwers, B. Dell, and G.E.J. Hardy, (2013), Sudden forest canopy collapse corresponding with extreme drought and heat in a mediterranean-type eucalypt forest in southwestern Australia. European Journal of Forest Research. 132: 497-510.

Mazdiyasni, O. and A. AghaKouchak, (2015), Substantial increase in concurrent droughts and heatwaves in the United States.Proceedings of the National Academy of Sciences of the United States of America, 112: 11484-11489.

Nolan, R.H., M.M. Boer, L. Collins, V. Resco de Dios, H. Clarke, M. Jenkins, et al. (2020) Causes and consequences of eastern Australia's 2019 - 2020 season of mega-fires. Global Change Biology . 26: 1039 1041.

Parsons, D.J., R. Dolores, T. Maliko and I.P. Holman, (2019), Regional variations in the link between drought indices and reported agricultural impacts of drought. Agricultural Systems , 173: 119-129.

Pendergrass, A.G. and R. Knutti, (2018) The Uneven Nature of Daily Precipitation and Its Change. Geophysical Research Letters , 45: 11980 - 11988.

Perry, M. and D. Hollis, (2005), The generation of monthly gridded datasets for a range of climatic variables over the UK.International Journal of Climatology, 25: 1041-1054.

Petrakis, S., A. Seyfferth, J. Kan, S. Inamdar, and R. Vargas, (2017), Influence of experimental extreme water pulses on greenhouse gas emissions from soils. Biogeochemistry, 133: 147-164.

R Core Team, (2019), R: A language and environment for statisical computing. 2019, R Foundation for Statiscal Computing: Vienna, Austria.

Reichstein, M., M. Bahn, P. Ciais, D. Frank, M.D. Mahecha, S.I. Seneviratne et al., (2013) Climate extremes and the carbon cycle. Nature, 500: 287.

Roudier, P., J.C.M. Andersson, C. Donnelly, L. Feyen, W. Greuell, and F. Ludwig, (2016) Projections of future floods and hydrological droughts in Europe under a $+2^{\circ} \mathrm{C}$ global warming. Climatic Change, 135: 341-355.

Rowland, C.S., D. Morton, L. Carrasci Tornero, G. McShane, A. O'Niel, and C. Wood, (2017), Land Cover Map 2015 (vector, GB). 2017, NERC Environmental Information Data Centre.

Schimel, J., T.C. Balser, and M. Wallenstein, (2007) Microbial stress-response physilogy and its implications for ecosystem function.Ecology , 88: 1386-1394.

Song, L., Y. Li, X. Wu, B. Guo, X. Tang, W. Shi, et al., (2019) Divergent vegetation responses to extreme spring and summer droughts in Southwestern China. Agricultural and Forest Meteorology, 279: 107703.

Stratford, C., J. Miller, A. House, G. Old, M. Acreman, M.A. Duenas-Lopez, et al. , (2017), Do trees in UK-relevant river catchments influence fluvial flood peaks? Centre for Ecology and Hydrology. 46 pp. 
Swain, D.L., B. Langenbrunner, J.D. Neelin, and A. Hall, (2018) Increasing precipitation volatility in twentyfirst-century California. Nature Climate Change, 8: 427-433.

The Guardian. 2019 was a bad year for floods and drought in England, say charities. 2020. Available from https://www.theguardian.com/environment/2020/mar/16/2019-was-bad-year-for-floods-and-droughtin-england-say-charities.

Thompson, V., N.J. Dunstone, A.A. Scaife, D.M. Smith, J.M. Slingo, S. Brown, et al., (2017) High risk of unprecedented UK rainfall in the current climate. Nature Communications , 8: 107.

Teuling, A.J., (2018), A hot future for European droughts. Nature Climate Change, 8: 364-365.

U.S. Government, (2018), U.S Drought Portal. [cited 2018 7/11/18]; Available from: https://www.drought.gov/drought/states/california.

Vogel, E., M.G. Donat, L.V. Alexander, M. Meinshausen, D.K. Ray, D. Karoly, et al. , (2019) The effects of climate extremes on global agricultural yields. Environ. Res. Lett. , 14: 054010.

Wood, S.N., (2017), Generalized additive models: an introduction with R. 2nd Edition ed. Texts in Statistical Science. Boca Raton, Florida:CRC Press . 146.

Wood, S.N., N. Pya, and B. Säfken, (2016), Smoothing Parameter and Model Selection for General Smooth Models. Journal of the American Statistical Association . 111: 1548-1563.

World Economic Forum, (2018), The Global Risks Report 2018. Geneva. p. pp66.

World Meteorological Organization, (2017), WMO guidelines on the claculation of climate normals. World Meterological Organization, Geneva, Switzerland. p. 29.

World Meteorological Organization, (2018) Draft guidelines on the definition and monitoring of extreme weather and climate events, World Meterological Organization : Geneva. p. 43pp.

Yin, J., P. Gentine, S. Zhou, S.C. Sullivan, R. Wang, Y. Zhang, et al., (2018), L arge increase in global storm runoff extremes driven by climate and anthropogenic changes. Nature Communications , 9: 4389.

Youngman, B.D. and T. Economou, (2017), Generalised additive point process models for natural hazard occurrence.Environmetrics, 28: e2444.

Zampieri, M., A. Ceglar, F. Dentener, and A. Toreti, (2017). Wheat yield loss attributable to heat waves, drought and water excess at the global, national and subnational scales. Environ. Res. Let. . 12: 064008.

Zhang, X., L. Alexander, G.C. Hegerl, P. Jones, A.K. Tank, T.C. Peterson, et al ., (2011) Indices for monitoring changes in extremes based on daily temperature and precipitation data. Wiley Interdisciplinary Reviews: Climate Change, 2: 851-870.

Zscheischler, J., A.M. Michalak, C. Schwalm, M.D. Mahecha, D.N. Huntzinger, M. Reichstein, et al. , (2014) Impact of large-scale climate extremes on biospheric carbon fluxes: An intercomparison based on MsTMIP data. Global Biogeochemical Cycles, 28: 585-600.

Acknowledgements All authors acknowledge the financial support provided by the Welsh Government and Higher Education Funding Council for Wales through the Sêr Cymru National Research Network for Low Carbon, Energy and Environment (SCNR-LCEE). We thank Alison Kingston-Smith, Dimitra Loka, Felicity Hayes, and Mike Humphreys for initial discussions on this project. We also acknowledge the valuable feedback provided by David Thomas and the SCNR-LCEE Management Board on the weather scenarios used here.

Figures and tables:

Main Text: 
Figure 1: Change in the annual frequency of threshold exceedance between the period 1961 - 1988 and 1989 - 2016. Positive numbers denote an increase and negative numbers denote a decrease. A value of 1.0 corresponds to one additional event per year and a value of - 1.0 corresponds to one fewer event per year. Areas of significant change $(\mathrm{p}<0.05)$ are denoted by hatching.

Figure 2: Change in the frequency of spells of (a) winter growing conditions and (b) spring dry spells between the period 1961 - 1988 and 1989 - 2016. Significant areas of change $(\mathrm{p}<0.05)$ denoted by hatching.

Figure 3: Total area (ha) of vulnerable ecosystem category exposed to a significant increase in the frequency of a) single stress event types and b) multiple stress event types.

Figure 4: Co-occurrence of a significant increase in the frequency of threshold exceedance of each event type at the $\mathrm{p}<0.05$ significant level (a) and the interaction with vulnerable land use category: agriculture (b) woodlands (c), Conservation areas (d) and carbon stores (e).

Table 1- Impact of the most prevalent extreme weather events on the main ecosystem services delivered within each land use type. The main ecosystem service is given in brackets where $P$ is provisioning, $R$ is regulation, $S$ is supporting and $C$ is cultural.

Supplementary document

Figure S1: Change in the frequency of extreme dry events between the period of 1961 - 1988 and 1989 -2016 during each meteorological season. Significant areas of change $(p<0.05)$ denoted by hatching.

Figure S2: Change in the joint probability that the annual mean count of two or more event categories exceed their respective thresholds between the period 1961-1988 and 1989-2016. These values lie in the region of - 1.0 to 1.0 and convey information on the change in the risk of (a) two, (b) three or (c) four extreme events occurring within the same year. Significant change was inferred for probabilities above 0.05 or below -0.05.

Table S1 - Summary of the risk and benefits of different extreme event stress on ecosystem service delivery based on and expert-led comprehensive review of the literature.

Table S2- Summary statistics of the change in probability that all four extreme event thresholds will be exceeded within the same year for the UK as a whole and for the individual regions defined by the Met Office in the accompanying figure.

\section{Hosted file}

Main text table.docx available at https://authorea.com/users/327697/articles/455154-spatialco-localization-of-extreme-weather-events-a-clear-and-present-danger 

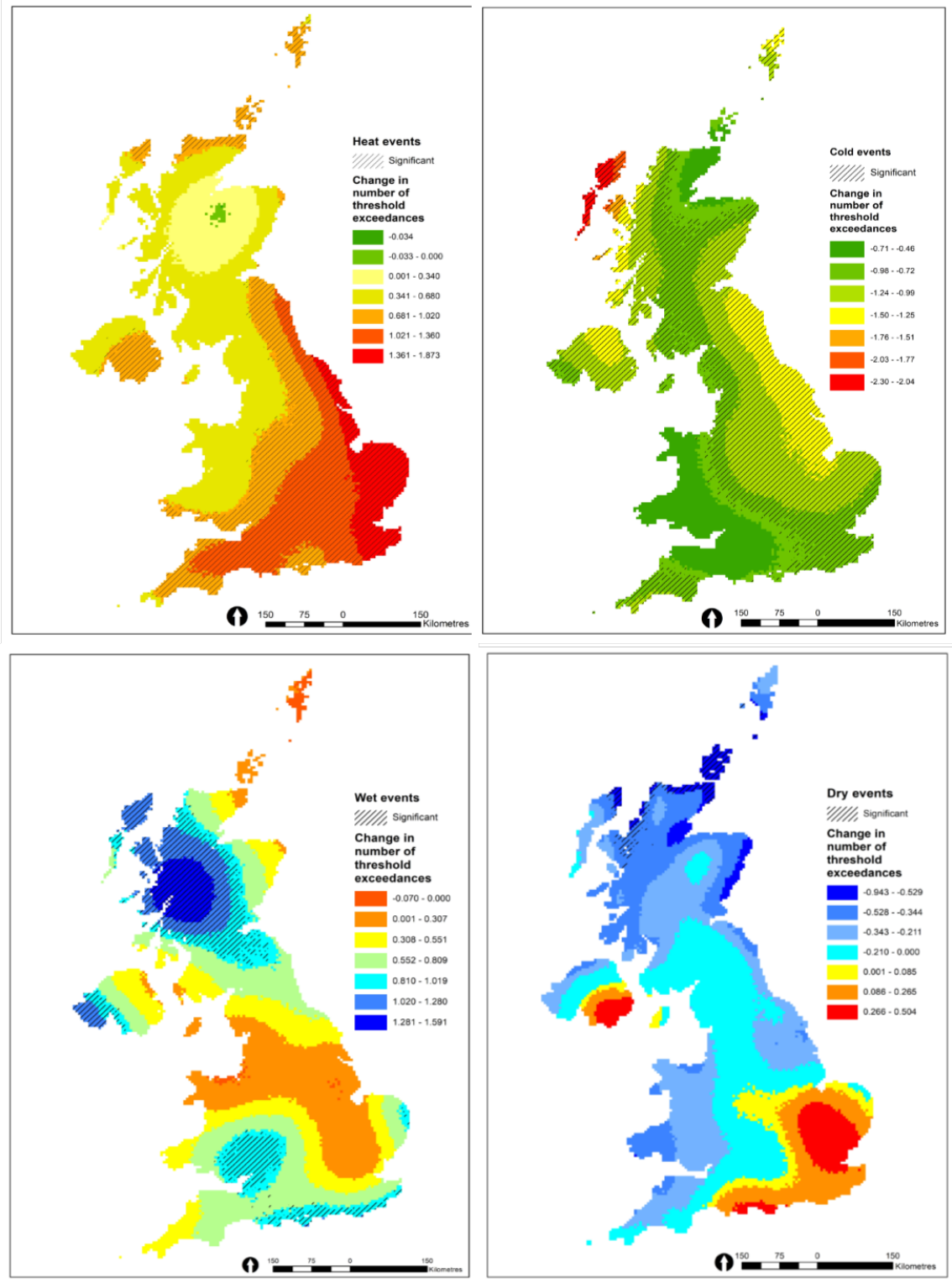

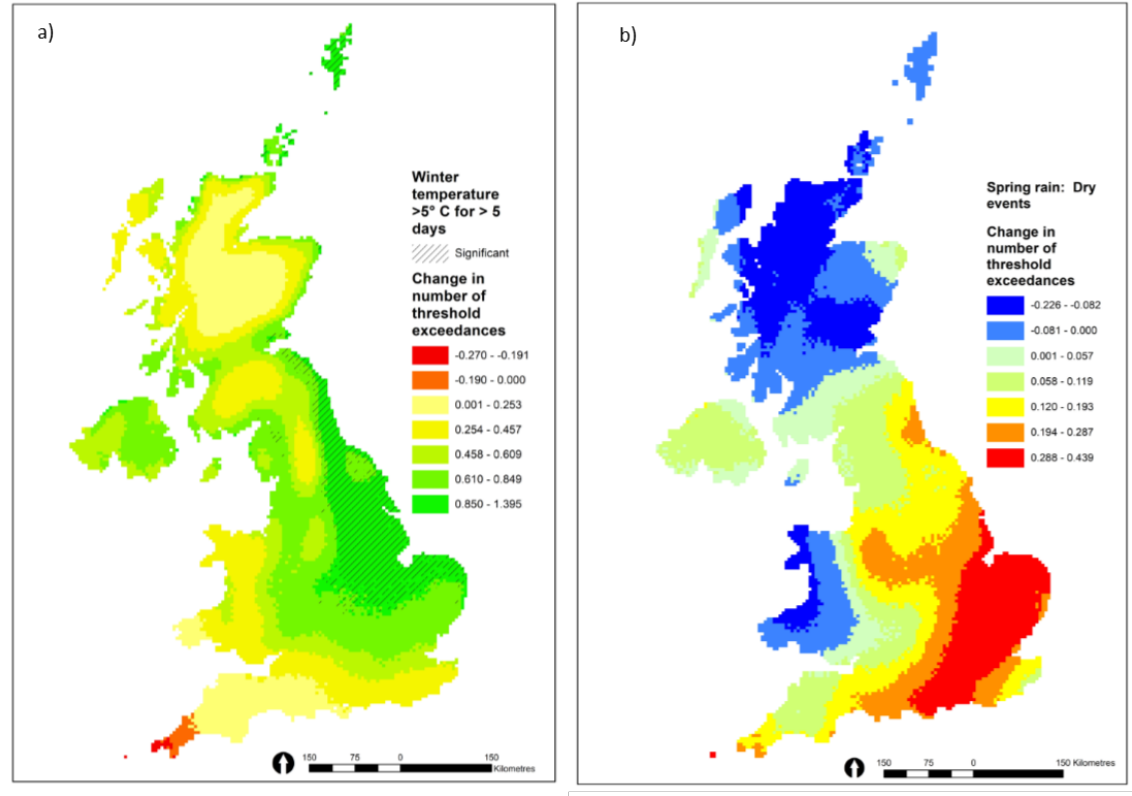

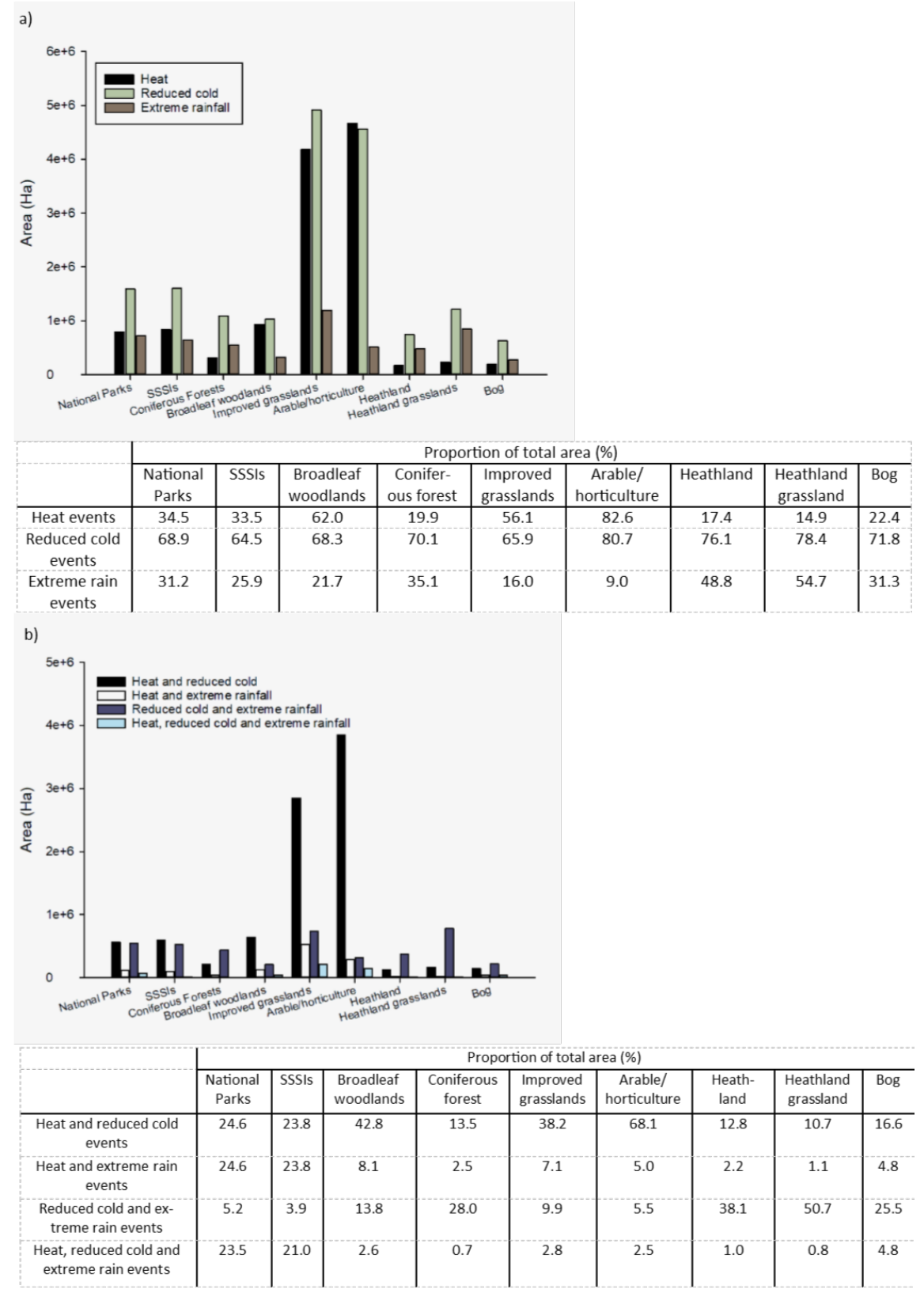


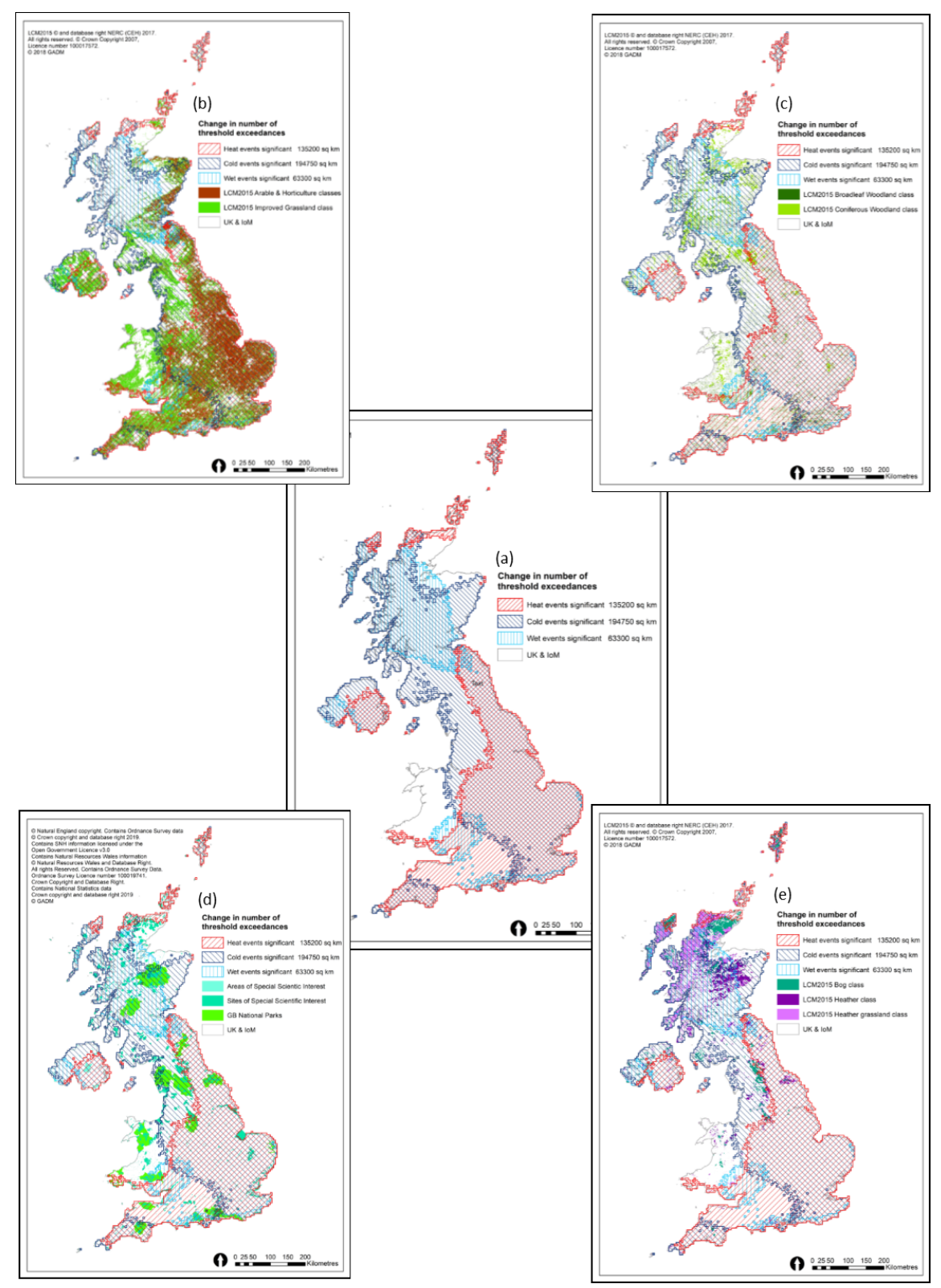

